\title{
INTERPRETATION OF THE ORIENTATION OF ICE DENDRITES GROWING FROM SUPERGOOLED WATER
}

\author{
By Laura Levi \\ (Consejo Nacional de Investigaciones Científicas y Técnicas, Rivadavia 1917, Buenos Aires, \\ Argentina)
}

\begin{abstract}
An interpretation is proposed of the phenomenon of splitting of ice dendrites growing from supercooled water and of their orientation at an angle $\alpha$ to the basal plane. Both phenomena are related to the instabilities which develop on the dendritic cap when the ratio $V_{c} / V_{a}$ of the growth velocities in the direction of the $c$ - and $a$-axes exceeds a certain limit. The different interface supercoolings, $\left(\delta T_{i}\right)_{a}$ and $\left(\delta T_{i}\right)_{c}$, at the tip and at the sides of the dendrite cap are considered. Although $V_{c} / V_{a}$ increases with the bath supercooling $\Delta T$ it is found that $V_{c} \ll V_{a}$ for $\left(\delta T_{i}\right)_{c}=\left(\delta T_{i}\right)_{a}$ through the whole range investigated $(0<\Delta T \leqslant 18 \mathrm{deg})$. The increase of $\alpha$ with the concentration of solutes is also qualitatively explained. Considering the kinetic theory of the molecular growth mechanism, the results obtained for $V_{c}$ as a function of $\left(\delta T_{1}\right)_{c}$ would indicate that most of the studied interval must correspond to the transitional regime of growth.

RÉsumÉ. Interprétation de l'orientation des dendrites de glace croissantes dans l'eau surfondue. On propose une interprétation du phénomène de scission des dendrites de glace croissantes dans l'eau surfondue et de son orientation d'un angle $\alpha$ du plan basal. On met ce phénomène en relation avec les instabilités qui se formeraient à l'extrémité de la dendrite, quand la rapport $V_{c} / V_{a}$ entre les vitesses de croissance dans la direction des axes $c$ et $a$ dépasse une certaine limite. On considère les différents refroidissements à l'interface $\left(\delta T_{\mathrm{i}}\right)_{a}$ et $\left(\delta T_{\mathrm{i}}\right)_{c}$ existents à l'extrémité et aux côtés de la pointe de la dendrite. On trouve que $V_{c} \ll V_{a}$ pour $\left(\delta T_{i}\right)_{c}=$ $=\left(\delta T_{\mathrm{i}}\right)_{a}$ dans tout l'intervale des températures étudié $(\mathrm{o}<\Delta T \leqslant \mathrm{i} 8 \mathrm{deg})$, bien que $V_{c} / V_{a}$ croisse avec le refroidissement de l'eau, $\Delta \mathcal{T}$. On explique aussi, qualitativement, l'observation que $\alpha$ croit avec la concentration d'une solution. En considérant la théorie cinétique du méchanisme moléculaire de solidification, on trouve que la dépendence de $V_{c}$ de $\left(\delta T_{i}\right)_{c}$ indique que l'interval étudié doit correspondre, dans sa plus grande partie, au régime de croissance de transition.

Zusammenfassung. Interpretation der Orientierung von in unterkühltem Wasser gewachsenen Eisdendriten. Es wird eine Interpretation für die Erscheinung der Spaltung von in unterkühltem Wasser gewachsenen Eisdendriten und ihrer Orientierung unter einem Winkel $\alpha$ gegen die Basisfläche vorgeschlagen. Beide Eigenschaften werden in Beziehung zu der Instabilität gebracht, welche am Dendritenkopf entstünde, wenn das Verhältnis $V_{c} / V_{a}$ der Wachstumsgeschwindigkeiten in Richtung der $c$ - und $a$-Achsen einen bestimmten Grenzwert unterschritte. Die unterschiedlichen Unterkühlungen $\left(\delta T_{i}\right)_{a}$ und $\left(\delta \mathcal{T}_{\mathbf{i}}\right)_{c}$ der Grenzflächen an der Spitze und an den Seiten des Dendritenkopfes werden betrachtet. Obgleich $V_{c} / V_{a}$ mit der Unterkühlung $\Delta T$ des Bades wächst, wurde über den gesamten untersuchten Bereich $\left(0<\Delta T \leqslant{ }_{1} 8 \mathrm{deg}\right)$ bei $\left(\delta T_{\mathrm{i}}\right)_{c}=\left(\delta T_{\mathrm{i}}\right)_{a} V_{c} \ll V_{c}$ gefunden. Ebenso wird das Wachsen von mit der Lösungskonzentration qualitativ erklärt. Bei Berücksichtigung der kinetischen Theorie des molekularen Wachstumsmechanismus führen die für $V_{c}$ als Funktion von $\left(T_{i}\right)_{c}$ erhaltenen Ergebnisse dazu, dass der grösste Teil des untersuchten Intervalls dem Zustand gleichmässigen Wachsens entsprechen muss.
\end{abstract}

\section{INTRODUCtion}

The growth process of ice dendrites from supercooled water has been studied for many years, because it was considered by metallurgists as a typical case of dendritic growth, and useful comparisons could be made with the features observed in other substances. Furthermore, the interest in ice dendrites has increased recently, due to their importance in problems of atmospheric physics. Several works have been published on their growth modes and velocity (Lindenmeyer, unpublished; Lindenmeyer and Chalmers, ig66; Hallett, r964; Macklin and Ryan, I965, I966, I968; Pruppacher, I967[a], [b]).

Special characteristics of these dendrites are their development as planar dendrites and their splitting and changes of orientation, which occur with increasing supercooling. According to Lindenmeyer (unpublished) and Macklin and Ryan (1968), the direction of the dendrite axis should coincide with that of the resultant of the growth velocities $V_{a}$ and $V_{c}$ in the direction of the $a$ - and $c$-axis respectively. This would be the direction of maximum growth velocity, given by:

$$
V=V_{a} \cos \alpha+V_{c} \sin \alpha .
$$

where $\alpha$ represents the inclination of the dendrites with respect to the basal plane. The 
increase of the angle $\alpha$ with the supercooling would then indicate an increase of the velocity ratio $V_{c} / V_{a}$.

This interpretation is not, however, directly supported by the theory of dendritic growth (Bolling and Tiller, I 96r). Actually, according to this theory, dendrites should have their axis in the direction of maximum growth velocity which simultaneously satisfies a condition of symmetry at the tip of the dendrite with respect to the crystalline structure. Then, as long as $V_{a}>V_{c}$, the axis of the dendrites should coincide with the $a$-axis and the increase of $V_{c} / V_{a}$ should only result in an increase in the dendrite thickness with respect to an ideal dendrite grown at the same supercooling.

In the present paper a mechanism is proposed to explain the splitting and inclination of ice dendrites which takes into account the hypothesis of Lindenmeyer and of Macklin and Ryan and also the theory of Bolling and Tiller.

For clarity, the experimental observations of the phenomenon and some points of the theory will be summarized below.

\section{EXPERIMENTAL EVIDENCE}

(a) Growth velocity in the direction of the a-axis. This velocity has been studied by several authors as a function of the bath supercooling $\Delta T$, and slightly different results have been obtained (Lindenmeyer, unpublished; Lindenmeyer and Chalmers, r966; Hallett, r964; Macklin and Ryan, I966, I968; Pruppacher, r967[b]). Following Pruppacher, $V_{a}$ can be expressed as

$$
V_{a}=0.035(\Delta T)^{2 \cdot 22} \text {. }
$$

The curve of $V_{a}(\Delta T)$ has been compared by Pruppacher to the corresponding theoretical curve, calculated by Bolling and Tiller ( $196 \mathrm{I}$ ). He shows that both curves might coincide if an interface supercooling $\left(\delta T_{i}\right)_{a}$ is supposed to exist at the tip of the dendrite, and he concludes that, in the range of temperatures investigated $\left(0^{\circ}\right.$ to $\left.-18^{\circ} \mathrm{C}\right)$, two intervals may be considered, so that

$$
\begin{array}{ll}
V_{a}=\mathrm{I} \cdot 3^{8}\left(\delta T_{\mathrm{i}}\right)_{a}^{2} & 0<\Delta T \leqslant 9 \mathrm{deg}, \\
V_{a}=2 \cdot 5^{\mathrm{o}}\left(\delta T_{\mathrm{i}}\right)_{a} & 9 \mathrm{deg} \leqslant \Delta T .
\end{array}
$$

In terms of the molecular mechanism of growth, the first interval should correspond to growth by lateral spreading of steps and the second to the continuous growth regime.

(b) Orientation of dendrites with respect to the basal plane. According to the measurements of several different authors (Lindenmeyer, unpublished; Macklin and Ryan, I965, r966, r968; Pruppacher, $\mathrm{I} 967[\mathrm{a}])$, the dendrites split, for $\Delta T>\mathrm{I}-2^{\circ} \mathrm{C}$, in symmetrical branches, forming between them an angle $2 \alpha$, which increases with $\Delta T$ and which tends to a limiting value $2 \alpha=45^{\circ}$ for $\Delta T>9 \mathrm{deg}$. This was shown specially clearly by Pruppacher, who extended his measurements down to $\Delta T=14 \mathrm{deg}$. For larger supercoolings direct measurements of $2 \alpha$ were not possible.

However in one case Hallett ( 1964$)$ was able to measure the growth velocity of dendrites in the direction of the $c$ and $a$ axes at $\Delta T=\mathrm{I} 6 \mathrm{deg}$ and deduced $\alpha=38^{\circ}$ at this supercooling. Furthermore there is indirect evidence that $2 \alpha$ should increase for $\Delta \mathcal{T}>\mathrm{I} 4 \mathrm{deg}$. It has been shown by Levi and Aufdermaur (1969) that, when ice structures formed by accretion and freezing of supercooled droplets are obtained with a surface temperature $<0^{\circ} \mathrm{C}$, the crystal $c$-axes tend to be oriented in the direction of growth, when the temperature of the air and of the arriving droplets are in the range $o>t_{a}>-8^{\circ} \mathrm{C}$. At colder temperatures $\left(-8>t_{a}>\right.$ $>-15^{\circ} \mathrm{C}$ ) the $c$-axes form with this direction an angle $10^{\circ}<\phi<30^{\circ}$, while they form an angle $\phi=45^{\circ}$ for $t_{a}=-\mathrm{I} 8$ or $-22^{\circ} \mathrm{C}$.

These different orientations of the crystal $c$-axes have been related to the different crystallographic orientations of the dendrites grown during the initial freezing of supercooled droplets. 
Then the value $\phi=45^{\circ}$ obtained for the lowest temperatures would indicate that $\alpha$ also reaches the same value for a temperature in the interval indicated above.

\section{General theory of Dendritic Growth}

It is known (Bolling and Tiller, 1961) that, for an ideal dendrite, the dendrite cap would be limited by an isothermal surface with the shape of a paraboloid of revolution. The conditions of optimization of the growth velocity $V$ indicate that the radius of curvature of the tip, $\rho / 2$, must satisfy the equation

$$
\frac{\rho}{2}=\frac{2 \gamma_{0}}{\Delta S\left(\Delta T-\left(\delta T_{i}\right)_{0}\right)}
$$

where $\Delta T$ and $\left(\delta T_{i}\right)_{0}$ are the bath and the interface supercooling respectively, $\Delta S$ is the entropy of fusion for unit volume and $\gamma_{0}$ is the surface free energy. Since the product $V \rho$ is approximately constant for a given supercooling, if $\rho$ increases according to Equation (5), then the velocity $V$ decreases.

It may be seen from Equation (5) that, for the maximization of $V$, the preferred direction with respect to the crystalline structure will be that which minimizes $\left(\delta T_{i}\right)_{0}$. On the other hand, if $V_{\phi}$ is the growth velocity in a direction forming an angle $\phi$ to the dendrite axis, it may be easily seen that, for the conservation of the tip shape, $V_{\phi}$ must be given by

$$
V_{\phi}=V_{\mathrm{o}} \cos \phi
$$

where $V_{\mathrm{o}}$ is the axial velocity.

Using $V=\mu\left(\delta T_{i}\right)$ as the general law for the solidification mechanism, where $\mu$ is a coefficient which may depend on the temperature, Equation (6) may be written

$$
\mu_{\phi}\left(\delta T_{i}\right)_{\phi}=\mu_{0}\left(\delta T_{i}\right)_{o} \cos \phi
$$

where $\left(\delta T_{\mathbf{i}}\right)_{0}$ and $\left(\delta T_{\mathbf{i}}\right)_{\phi}$ are the interface supercoolings in the axial direction and in a direction forming the angle $\phi$ with this axis. These supercoolings are related by the expression

$$
\left(\delta T_{\mathrm{i}}\right)_{\phi}=\left(\delta T_{\mathrm{i}}\right)_{0}+\frac{\gamma_{\mathrm{o}}}{\Delta S}\left(\frac{2}{\rho}-\frac{\gamma_{\phi} / \gamma_{0}}{R}\right)
$$

where $\gamma_{0}$ and $\gamma_{\phi}$ are the surface free energies in the axial direction and at an angle $\phi$ to the axis and $R$ is the radius of curvature of the region of the surface characterized by the angle $\phi$.

For an isothermal dendrite the radius of curvature $R$ has the expression

$$
\frac{\mathrm{I}}{R}=\frac{\cos \phi\left(\mathrm{I}+\cos ^{2} \phi\right)}{\rho} .
$$

Since according to Equations (8) and (9) $R>\rho / 2$ and $\left(\delta T_{\mathrm{i}}\right)_{\phi} \geqslant\left(\delta T_{\mathrm{i}}\right)_{0}$, it also follows from Equation (7) that, for an isothermal dendrite, $\mu_{\phi} \leqslant \mu_{0} \cos \phi$. When this condition is not satisfied, the surface of an isothermal dendrite becomes unstable. Then, the radius of curvature at the tip should increase above the limit given by Equation (5). The dendrite would get thicker and the growth velocity lower.

\section{INTERPRETATION OF ICE DENDRITE Characteristics}

(a) Mechanism of splitting and irrational orientation of the dendrites. We will consider an ice dendrite growing initially in the direction of the $a$-axis. It has been assumed by Bolling and Tiller that the tip of a dendrite should usually tend to be limited by low index planes. In the case of ice, these planes are $\{$ I $о \bar{I} O\}$ and (OOOI), the latter containing the dendrite axis. Then two sides of the dendrite tip will be limited by two $\{$ Io $\overline{0} 0\}$ planes $\left(\phi=60^{\circ}\right)$, but the other sides, normal to the first ones, should be formed by higher index surfaces, each of them tending to a (OOOI) plane $\left(\phi=90^{\circ}\right)$ at some distance from the tip. 
We see from Equation (9) that the radius of curvature $R$ will tend to $\infty(\mathrm{r} / R \rightarrow 0)$ for $\phi \rightarrow 90^{\circ}$ and Equation (8) may be simplified to

Using Equation (5) this may also be written

$$
\left(\delta T_{\mathrm{i}}\right)_{9_{0}} \approx\left(\delta T_{\mathrm{i}}\right)_{0}+\frac{\gamma_{\mathrm{o}}}{\Delta S} \frac{2}{\rho} .
$$

$$
\left(\delta T_{\mathrm{i}}\right)_{90} \approx \frac{1}{2}\left(\Delta T+\left(\delta T_{\mathrm{i}}\right)_{\mathrm{o}}\right) .
$$

From Equation $\left(\mathrm{Io}^{\prime}\right),\left(\delta T_{\mathrm{i}}\right)_{90}$ is obtained easily, since the value of $\left(\delta T_{\mathrm{i}}\right)_{0}$ corresponding to a given $\Delta T$ may be calculated by applying Pruppacher's results ( $1967[\mathrm{~b}]$ ) represented by Equations (3) or (4) and by the experimental curve of $V$ as a function of $\Delta T$ (represented by Equation (2) for $\Delta T<9^{\circ} \mathrm{C}$ ). Some values of these supercoolings are given in the last columns of Table I. Here $\left(\delta T_{\mathrm{i}}\right)_{0}$ and $\left(\delta T_{\mathrm{i}}\right)_{9_{0}}$ have been represented by $\left(\delta T_{\mathrm{i}}\right)_{a}$ and $\left(\delta T_{\mathrm{i}}\right)_{c}$ respectively, to indicate the corresponding crystallographic direction. The table shows that $\left(\delta T_{\mathrm{i}}\right)_{c} \approx$ $\approx 3\left(\delta T_{\mathrm{i}}\right) a$ and that the ratio of these supercoolings varies very slowly with the temperature.

TABLE I. GRoWth Velocities AND INTERFACE SUPERCOOLINGS PARALlEL TO IN $a$ - AND $c$-AXES

$\begin{array}{rccccc}\begin{array}{r}\Delta T \\ \operatorname{deg}\end{array} & \alpha & \begin{array}{c}V_{a} \\ \mathrm{~cm} / \mathrm{s}\end{array} & \begin{array}{c}V_{c} \\ \mathrm{~cm} / \mathrm{s}\end{array} & \begin{array}{c}\left(\delta T_{\mathrm{i}}\right)_{a} \\ \operatorname{deg}\end{array} & \begin{array}{c}\left(\delta T_{\mathrm{i}}\right)_{c} \\ \operatorname{deg}\end{array} \\ 2 & 4^{\circ} 36^{\prime} & 0.15 & 0.014 & 0.3 & 1 . \mathrm{I} \\ 4 & 98^{\prime} & 0.9 & 0.14 & 0.8 & 2.4 \\ 6 & 13^{\circ} 4^{\prime} & 2.0 & 0.5 & 1.2 & 3.6 \\ 8 & 18^{\circ} 24^{\prime} & 4.0 & 1.3 & 1.7 & 4.9 \\ 18 & 45^{\circ} & 10.0 & 10.0 & 4.0 & 11.0\end{array}$

On the other hand, it may be observed from Equations (8) and (9) that the variation of $\left(\delta T_{i}\right)_{\phi}$ with the angle $\phi$ must be more pronounced for $\phi>45^{\circ}$ than in the vicinity of the tip. Actually, for $\phi<45^{\circ}$, $\cos \phi$ decreases slowly and $\gamma_{\phi}$ probably increases because the index of the surface increases; on the contrary, for $\phi>45^{\circ}$, the variation of $\cos \phi$ is faster and $\gamma_{\phi}$ should decrease, tending to a minimum value for $\phi=90^{\circ}$. Then, in the region of large $\phi$, where $\left(\delta T_{\mathrm{i}}\right)_{\phi}$ increases rapidly, the approximately paraboloidal cap of the dendrite would become unstable, and for $V_{c} / V_{a}$ larger than a given limit, a protuberance could be formed on the surface.

Now, since the radius of curvature at the tip of the protuberance will be smaller than that of the original dendrite, its growth velocity will be higher and the protuberance will overtake the dendritic tip. Then, if we start with an initially basal dendrite, two symmetrical instabilities will be formed at both sides of the tip and the phenomenon will determine the splitting of the dendrite.

After the splitting, the thermal interaction between the two symmetrical branches will hinder the splitting phenomenon on the inside surfaces and the instability effect will operate periodically only on the outside surfaces, determining the inclination of the dendrites. However, with the increase of the distance between the two advancing tips, the interaction will decrease and new splittings will take place, the more frequently the larger the value of $\alpha$.

According to this interpretation, the growth direction of a dendrite would be the resultant of the advance of the dendrite tip in the direction of the $a$-axis and of its shifting in the direction of the $c$-axis because of the formation of lateral layers. Accordingly, Equation (I) would be maintained and, for a given bath supercooling $\Delta T$, the velocity $V_{c}$ could be obtained from $V_{a}$ (as indicated by Macklin and Ryan ( 1968$)$ ), by means of the expression

$$
V_{c}=V_{a} \tan \alpha
$$

though the values of $V_{c}$ and $V_{a}$ would correspond to different interface supercoolings.

(b) Effect of the temperature on the ratio $V_{c} / V_{a}$. In Table I $V_{a}$ and $V_{c}$ have been calculated for several values of $\Delta T$. Because of the uncertainty of the results in the range $9 \leqslant \Delta T \leqslant 14$ 
$\operatorname{deg}$ (Pruppacher, I967[b]), the calculated points are taken in the interval o $<\Delta T<9 \mathrm{deg}$, with the exception of the last point, at $\Delta T \approx \mathrm{r} 8 \mathrm{deg}$.

As observed by previous authors (Hallett, r964; Macklin and Ryan, I966), the results show that, if only the bath supercooling is considered, $V_{c}$ increases rapidly with respect to $V_{a}$ with increasing $\Delta T$, reaching approximately the same value when $\Delta T$ approaches $18 \mathrm{deg}$. It could now be of interest to compare pairs of values of $V_{a}$ and $V_{c}$ corresponding to the same interface supercooling. This may be done if we observe that, in Table $\mathrm{I},\left(\delta \mathcal{T}_{\mathrm{i}}\right)_{c}$ for $\Delta T=2$ deg approximately coincides with $\left(\delta T_{\mathrm{i}}\right)_{a}$ corresponding to $\Delta T=6 \mathrm{deg}$ and similarly that $\left(\delta T_{\mathrm{i}}\right)_{c}$ for $\Delta T=8 \mathrm{deg}$ may be compared with $\left(\delta T_{\mathrm{i}}\right)_{a}$ for $\Delta T \approx \mathrm{I} 8 \mathrm{deg}$. Therefore

$$
\begin{aligned}
& V_{c} / V_{a} \approx 7 \times 10^{-3} \quad \text { for } \quad\left(\delta \mathcal{T}_{\mathrm{i}}\right) \approx \mathrm{I} \mathrm{deg}, \\
& V_{c} / V_{a} \approx 1.3 \times 10^{-1} \quad \text { for } \quad\left(\delta T_{\mathrm{i}}\right) \approx 4 \mathrm{deg},
\end{aligned}
$$

and we see that, if the same interface supercooling is considered, then, through the whole studied range, $V_{c} \ll V_{a}$, though the ratio of these velocities evidently decreases with increasing $\left(\delta T_{\mathrm{i}}\right)$.

It should be noted that the values of $\alpha$ and $V_{c}$ in the last line of the table have been indicated as approximate; this, as mentioned before, is because of the uncertainty of the accretion experiments, and also because, if the present interpretation is correct, the value $\alpha=45^{\circ}$ would not correspond to a single value of $\Delta T$ but should remain constant over a certain temperature interval and possibly represent a limiting value. In fact, it is easy to see that $\alpha>45^{\circ}$ could take place only when $V_{c}>V_{a}$ for $\left(\delta T_{\mathrm{i}}\right)_{c} \leqslant\left(\delta T_{\mathrm{i}}\right)_{a}$, i.e. when the $c$ - and $a$ axes interchange their role in the growth of dendrites. Then there would be an interval of temperatures where an increase of the ratio $V_{c} / V_{a}$ could only determine an increase of the dendrite thickness with respect to the theoretical thickness of isothermal dendrites at the same supercooling.

Experimentally it has been found in accretion experiments, that the orientation of the $c$-axis of crystals to the growth direction reached $45^{\circ}$ at an air temperature of $-18^{\circ} \mathrm{C}$ and remained at this orientation down to the lowest temperature of the experiments, $-22^{\circ} \mathrm{C}$ in similar injection conditions. This result is in agreement with the above observation, though it must be noted that this interval of air temperature, of only $4 \mathrm{deg}$, may not be considered as a definitive proof of the effect under discussion.

(c) Dendrite width and thickness. According to the mechanism of splitting and inclination of ice dendrites proposed here, the dendrite tip should always point with its region of maximum curvature in the direction of the $a$-axis. This is in agreement with the schematic representation proposed initially by Macklin and Ryan (1965). However, later on (Macklin and Ryan, I966), the same authors assumed the dendrite tip was oriented as the main body of the dendrite. It may be noted that the latter hypothesis encounters some difficulty if the thickness of the dendrites is considered. In fact, since in this case, on increasing $\Delta T, V_{c}$ would approach $V_{a}$ for the same interface supercooling, the growth velocity should become of the same order of magnitude in all directions and the dendrites should increase in thickness, independently of their orientation (non-isothermal dendrites). On the other hand it is known (Pruppacher, I $967[\mathrm{a}]$ ) that the ice dendrites become very thin on increasing the supercooling. Their thickness has not been studied in detail, but some measurements exist of their width in the basal plane (Hallett, I 964 ), which may be used for comparison.

In the first column of Table II the width of the dendrites (secondary branches), obtained from Hallett's curves, is given for a few temperatures. From these values, the radius of curvature at the tip, $\frac{1}{2} \rho$, has been obtained considering in the calculations the dendrite cap as a paraboloid of revolution and supposing that the width $(=2 R)$ was measured at about I $\mathrm{mm}$ from the tip (as may be deduced from Hallett's figures). The results are represented in the third column of the table $\left(\frac{1}{2} \rho\right.$ exp.). Finally the theoretical values of $\frac{1}{2} \rho$, shown in the fourth column, were obtained by Bolling and Tiller (r96r), as an application of the theory of 
non-isothermal dendrites. The comparison of the figures in the third and the fourth column shows that the development of the ice dendrites in the basal plane is in approximate agreement with the theoretical results.

TAble II. Radius of curvature at the tip of DENDRites In the Basal Plane

$\begin{array}{cccc}\Delta T & \text { Width } & \frac{1}{2} \rho \exp . & \frac{1}{2} \rho \text { theor. } \\ \operatorname{deg} & \mu \mathrm{m} & \mu \mathrm{m} & \mu \mathrm{m} \\ 1.6 & 42 & 0.45 & 0.50 \\ 3.7 & 26 & 0.17 & 0.13 \\ 4.8 & 20 & 0.10 & 0.11\end{array}$

Since these dendrites are, over the whole range studied, much thinner than they are wide, it follows that the theory of non-isothermal dendrites should not be applied to calculate their thickness and so $V_{c} \ll V_{a}$ for the same interface supercooling, in agreement with the present interpretation.

(d) Modification of the angle $\alpha$ for ice dendrites growing in aqueous solutions. The growth velocity and the angle $2 \alpha$ have been measured in aqueous solutions of several electrolytes by Lindenmeyer (unpublished) and by Pruppacher (1967[a]) and in solutions of sucrose by Macklin and Ryan (1966, I968). The results are very similar. They show that the presence of a solute in water decreases the growth velocity and increases the angle $2 \alpha$. The effect is nearly independent of the solute substance.

So, for electrolyte solutions of a concentration $10^{-1} \mathrm{~N}$, the limiting value of $2 \alpha$ (similar to the limit $2 \alpha=45^{\circ}$ for pure water) is shifted to $2 \alpha=60^{\circ}$. This is reached for instance at $\Delta T=4 \mathrm{deg}$ and at $\Delta T=6 \mathrm{deg}$ for $\mathrm{Na}$ salts and for $\mathrm{NH}_{3}$ salts respectively. Macklin and Ryan (1968) do not give the angle $2 \alpha$ directly, but they plot the growth velocities $V_{a}$ and $V_{c}$ as a function of $\Delta T$. By comparing the curves the angle $2 \alpha$ may be calculated and the limit value is obtained again at $2 \alpha \approx 60^{\circ}$ for a $10^{-1} \mathrm{~N}$ sucrose solution (reached at $\Delta T \approx 4 \mathrm{deg}$ ).

Macklin and Ryan also indicate that the initial temperature of splitting $\Delta T_{0}$ is increased for solutions as compared with pure water, being for instance $\Delta T_{\mathrm{o}}=1.2 \mathrm{deg}$ for a $\mathrm{IO}^{-1} \mathrm{~N}$ and $\Delta T_{0}=0.2 \mathrm{deg}$ for a $2 \times 10^{-1} \mathrm{~N}$ sucrose solution (the same authors give $\Delta T_{0}=2.7 \mathrm{deg}$ for pure water).

It is known that the inhibition of the growth velocity caused by the presence of a solute is related to the concentrated layer formed at the interface of the advancing tip (Bolling and Tiller, I96I) which reduces the melting point and consequently the effective interface supercooling with respect to the bath supercooling. Now, according to the interpretation of the splitting and inclination of dendrites proposed here, the concentration gradient existing near the dendrite tip could also be the cause of the increase of $\alpha$. Actually, since the lateral growth is much slower than the advance of the tip, the concentration layer may get diluted along the dendrite body. Supposing this part of the dendrite can be considered as approximately isothermal, the interface supercooling should increase at some distance from the tip and consequently the effects of the lateral instabilities considered above should also increase.

This interpretation would explain why the effect depends very little on the particular substance used as a solute. It would also eliminate the contradiction observed by Pruppacher (1967[a]) with the results obtained for ice growing in capillaries*, according to which the growth velocity of ice in the direction of the $c$-axis, measured in other experiments, would be slightly inhibited by the presence of small concentrations of some electrolyte. In fact, this would be a minor effect compared with the change of the interface concentration along the dendrite body.

\footnotetext{
* This contradiction has been observed by Pruppacher ( $1967[\mathrm{a}]$ ), who also cites Farrar (unpublished) and Sperry (unpublished). For the present article, these two items could not be consulted.
} 
On the other hand, this kind of explanation could not be applied if the interpretation of the irrational growth of ice dendrites given by Macklin and Ryan (1966) is accepted, because in this case the phenomenon would not be related to the different supercoolings existing at different points of the dendrite cap.

\section{Conclusions}

The results discussed above may now be used to obtain the law of the growth velocity of ice in the direction of the $c$-axis as a function of $\left(\delta T_{\mathrm{i}}\right) c$.

In the interval of bath supercoolings $2 \mathrm{deg} \leqslant \Delta T \leqslant 8 \mathrm{deg}$,

$$
V_{c}=0.0 \mathrm{I}\left(\delta T_{\mathrm{i}}\right)_{c}^{3} \text {. }
$$

The average exponent $n$ of $\left(\delta \mathcal{T}_{\mathbf{i}}\right)_{c}$ is slightly smaller in the last interval of Table I, $8 \mathrm{deg}<$ $<\Delta T<\mathrm{I} 8 \mathrm{deg}$, where it is $n \approx 2.5$.

According to the general theory of the molecular mechanism of growth, Equation (I3) should correspond well enough in the interval of temperatures where the transitional growth regime prevails $(n>2$ according to Cahn and others (1964)). This regime represents the transition between the growth by lateral spreading of steps $(n=2)$ and the continuous regime $(n=\mathrm{I})$.

As observed by Hallett (1964) and by Pruppacher (1967[a]), previous results on the growth of ice in capillaries in the direction of the $c$-axis, for $\Delta T \leqslant \mathrm{I} \mathrm{deg}$, indicate that in these conditions the growth velocity increases much more slowly than predicted by Equation (13). Though the present and previous results are not strictly comparable because of the different growth methods used, this difference seems to indicate that the transition supercooling $\left(\delta T_{\mathrm{i}}\right)_{c}^{\star}$ between the growth by lateral spreading of steps and the transitional regime must be found near the low limit of Table $I\left(\left(\delta T_{\mathrm{i}}\right)_{c}^{\star} \leqslant \mathrm{I} \mathrm{deg}\right)$. According to Pruppacher a similar transition in the direction of the $a$-axis should take place at $\left(\delta T_{i}\right)_{a}^{\star}=0.5^{8} \mathrm{deg}$. Then, if we do not discuss here the difference between the laws represented by Equations (3) and (13), and we admit that both of them may represent the transitional regime, in spite of the different exponent of $\left(\delta T_{\mathrm{i}}\right)$, we should conclude that the transition temperatures depend very little on the growth direction. Consequently, since (Cahn and others, ig64)

$$
\left(\delta T_{\mathrm{i}}\right)_{a}^{\star}=g \gamma v_{\mathrm{s}} T_{\mathrm{m}} / a L
$$

where $v_{\mathrm{s}}$, the molecular volume of the solid, $\mathcal{T}_{\mathrm{m}}$, the melting point, $a$, the step height, $L$, the latent heat of fusion and $\gamma$ are all constants, the parameter $g$, which is a measure of the diffuseness of the surface, should be approximately the same $\left(g \approx \mathrm{IO}^{-2}\right.$ according to Pruppacher

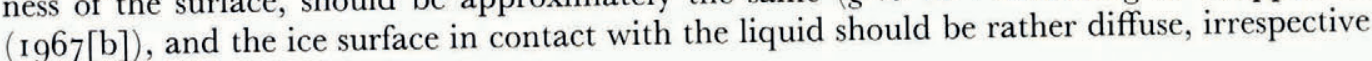
of its orientation.

\section{Acknowledgements}

The author is grateful to D. Fainstein for helpful discussions and to E. Achaval for reading the text.

MS. received ${ }_{15}$ February 1969 and in revised form 29 July 1969

\section{REFERENCES}

Bolling, G. F., and Tiller, W. A. 1961. Growth from the melt. III. Dendritic growth. Fournal of Applied Physics, Vol. 32 , No. 12, p. 2587-605.

Cahn, J. W., and others. 1964. The molecular mechanism of solidification, by J. W. Cahn, W. B. Hillig and G. W.

Sears. Acta Metallurgica, Vol. 12, No. 12, p. I421-39.
Hallett, J. 1964. Experimental studies of the crystallization of supercooled water. Fournal of the Atmospheric Sciences, Vol. 21, No. 6, p. 671-82. 
Levi, L., and Aufdermaur, A. N. 1969. Orientation of ice crystals grown by accretion of supercooled droplets. (In Riehl, N., and others, ed. Physics of ice: proceedings of the international symposium on physics of ice, Munich, Germany, September 9-14, 1968. Edited by $\mathcal{N}$. Riehl, B. Bullemer, H. Engelhardt. New York, Plenum Press, p. 620-30.)

Lindenmeyer, C. S. Unpublished. The solidification of supercooled aqueous solutions. [Ph.D. thesis, Harvard University, 1959.] Lindenmeyer, C. S., and Chalmers, B. 1966. Growth rate of ice dendrites in aqueous solutions. Fournal of Chemical
Physics, Vol. 45, No. 8, p. 2807-08.

Macklin, W. C., and Ryan, B. F. $196_{5}$. The structure of ice grown in bulk supercooled water. Fournal of the Atmospheric Sciences, Vol. 22, No. 4, p. $45^{2-59}$

Macklin, W. C., and Ryan, B. F. 1966. Habits of ice grown in supercooled water and aqueous solutions. Philosophical Magazine, Eighth Ser., Vol. 14, No. I30, p. 847-6o.

Macklin, W. C., and Ryan, B. F. 1968. Growth velocities of ice in supercooled water and aqueous sucrose solutions. Philosophical Magazine, Eighth Ser., Vol. I 7, No. 145, p. 83-87. Pruppacher, H. R. I967[a]. Growth modes of ice crystals in supercooled water and aqueous solutions. Fournal of
Glaciology, Vol. 6, No. 47, p. $65 \mathrm{I}-62$.

Pruppacher, H. R. ${ }^{967}$ [b]. Interpretation of experimentally determined growth rates of ice crystals in supercooled water. Fournal of Chemical Physics, Vol. 47, No. 5, p. 1807-13. 